\title{
PROFILE MATCHING SEBAGAI EVALUASI IMPLEMENTASI SISTEM INFORMASI PENDAFTARAN PASIEN IGD RSUD PASAR REBO
}

\author{
Dona Katarina ${ }^{1}$, Erlin Windia Ambarsari ${ }^{2}$ \\ ${ }^{1}$ Universitas Indraprasta PGRI \\ Jl Nangka No. 58C Tanjung Barat Jagakarsa, Jakarta Selatan, Jakarta \\ ${ }^{1}$ dona.katrin@gmail.com \\ ${ }^{2}$ Universitas Indraprasta PGRI \\ Jl Nangka No. $58 C$ Tanjung Barat, Jakarta Selatan, Jakarta \\ 2erlinunindra@gmail.com
}

\begin{abstract}
ABSTRAK
Perkembangan teknologi pada masyarakat Indonesia semakin meningkat antara lain kebutuhan pelayanan kesehatan terutama RSUD Pasar Rebo, karena itu untuk mempermudah pelayanan kesehatan khususnya IGD yang harus mendapatkan pertolongan cepat maka dibuat sistem informasi pendaftaran pasien IGD dengan tujuan mempermudah proses pendaftaran pasien, penanganan data sensus harian pasien dan pembuatan laporan kunjungan pasien. Permasalahan yang terjadi pada sistem informasi tersebut adalah apakah sudah benar-benar sesuai dengan kebutuhannya sehingga perlu dilakukan penilaian dengan melakukan evaluasi implementasi sistem. Metode yang digunakan untuk evaluasi adalah Profile Matching sebagai sistem keputusan untuk menganalisis sistem informasi tersebut, dimana kriteria yang dipertimbangkan antara lain Maintainability, Dependability, Efficiency dan Usability. Kesimpulan yang didapatkan dari Profile Matching adalah Sistem Informasi Pendaftaran Pasien IGD RSUD Pasar Rebo dapat dikatakan sesuai dengan kebutuhan (user friendly) dan mempermudah pekerjaan RSUD Pasar Rebo dalam penanganan pasien IGD.
\end{abstract}

Kata kunci: Sistem Informasi, Evaluasi Implementasi Sistem, Profile Matching

\section{PENDAHULUAN}

Perkembangan teknologi semakin meningkat karena didorong oleh kebutuhan masyarakat Indonesia untuk segala aktivitas yang serba praktis terutama pada teknologi informasi yang tidak kalah bersaing dalam pengolahan data khususnya di bidang pelayanan kesehatan. RSUD Pasar Rebo merupakan salah satu rumah sakit umum daerah milik pemerintah yang terletak di Jakarta Timur yang menyediakan pelayanan kesehatan.

Salah satu pelayanan kesehatan yang ada di RSUD Pasar Rebo adalah Instalasi Gawat Darurat (IGD). Pelayanan IGD merupakan tindakan untuk memberi pertolongan pertama bagi pasien untuk menghindari resiko seperti kematian, menanggulangi korban kecelakaan, atau bencana lainnya yang langsung membutuhkan tindakan, karena itu sebagai penunjang mempermudah pelayanan kesehatan IGD yang harus mendapatkan pertolongan cepat dalam teknologi informasi maka dibuat sistem informasi pendaftaran pasien IGD dengan tujuan mempermudah proses pendaftaran pasien, penanganan data sensus harian pasien dan pembuatan laporan kunjungan pasien RSUD Pasar Rebo (Katarina, 2003).

Permasalahan yang terjadi pada sistem informasi tersebut adalah apakah sudah benar-benar sesuai dengan kebutuhannya sehingga perlu dilakukan penilaian dengan melakukan evaluasi implementasi sistem. Kebutuhan yang dimaksud adalah indikator-indikator sebagai alat ukur pemenuhan kualitas yang sesuai dengan sasaran pengguna. Metode yang digunakan untuk evaluasi adalah Profile Matching sebagai sistem keputusan untuk menganalisis sistem informasi yang telah dibuat. Profile Matching merupakan suatu metode berdasarkan tingkat variabel prediktor ideal yang diharapkan dapat membantu penilaian sistem informasi pendaftaran pasien IGD secara obyektif.

Sistem keputusan tersebut berdasarkan penilaian sistem informasi pendaftaran dilakukan dengan mempertimbangan kinerja dari suatu sistem dimana konsepnya seperti yang dilakukan oleh (Kristiana, 2015) dengan penilaian kinerja pegawai negeri sipil (PNS) yang dapat memberikan nilai secara obyektif dengan standar kriteria yang telah ditentukan dengan metode Profile Matching.

Penelitian ini merupakan penelitian lanjutan dari penelitian (Katarina, 2003) dengan judul Analisis Dan Desain Sistem Informasi Pendaftaran Pasien IGD Di RSUD Pasar Rebo dengan mengevaluasi kinerja sistem saat dilakukan implementasi menggunakan metode Profile Matching diharapkan sistem informasi tersebut tepat guna dan dimanfaatkan secara kontinu oleh pihak RSUD Pasar Rebo.

\section{LANDASAN TEORI}

\section{A. Pengambilan Keputusan}

Keputusan untuk mengevaluasi sistem informasi pendaftaran pasien IGD merupakan rangkaian tindakan yang perlu diikuti dalam memecahkan masalah agar menghindari dampak negatif atau memanfaatkan 
kesempatan. Pengambilan keputusan dapat mengikuti empat fase yaitu Intelligence, Design, Choice, dan Implementation (Turban, Sharda, \& Delen, 2011)

1) Intelligence; meliputi analisa lingkungan, baik secara bertahap maupun berkesinambungan. Termasuk kegiatan mengidentifikasi masalah atau kesempatan, memonitor hasil fase Implementation.

2) Design; meliputi kegiatan menemukan atau mengembangkan dan menganalisa kemungkinan alternatif solusi, termasuk kegiatan memahami masalah dan menguji beberapa kemungkinan solusi.

3) Choice; tahapan kritis dalam pengambilan keputusan untuk mengikuti arah tertentu dari tindakan yang telah terpilih dilakukan yang meliputi aktivitas mencari, mengevaluasi dan merekomendasikan sebuah solusi yang sesuai dengan model untuk beberapa variabel keputusan dalam sebuah alternatif terpilih.

4) Implementation; sebuah tindakan dilakukan sebagai bentuk realisasi dari pemilihan sebuah solusi dari masalah yang ada.

\section{B. Profile Matching}

Pengambilan keputusan dalam evaluasi implementasi sistem menggunakan metode Profile Matching, dimana dengan mengasumsikan bahwa terdapat tingkat variabel prediktor yang ideal yang harus dimiliki oleh individu, bukan tingkat minimal yang harus dipenuhi atau dilewati (Fiati, 2015).

Profile Matching merupakan proses membandingkan kompetensi individu menjadi kompetensi posisi yang dapat diketahui perbedaannya atau dapat disebut dengan gap (Nasyriyah, Arham, \& Aini, 2016). Gap yang dimaksud adalah perbedaan atau selisih value masing-masing aspek atau atribut dengan value target (Fiati, 2015), dimana rumus yang digunakan adalah sebagai berikut :

$$
G A P=\text { value atribut }- \text { value target }
$$

Gap tersebut kemudian diberikan nilai bobot seperti pada tabel dibawah ini :

Tabel 1. Bobot Nilai Gap

\begin{tabular}{|c|c|c|l|}
\hline No & Selisih & $\begin{array}{c}\text { Bobot } \\
\text { Nilai }\end{array}$ & \multicolumn{1}{|c|}{ Keterangan } \\
\hline 1 & 0 & 5 & $\begin{array}{l}\text { Tidak ada selisih } \\
\text { Kompetensi sesuai dengan } \\
\text { yang dibutuhkan) }\end{array}$ \\
\hline 2 & 1 & 4,5 & $\begin{array}{l}\text { Kompetensi individu } \\
\text { kelebihan satu tingkat }\end{array}$ \\
\hline 3 & -1 & 4 & $\begin{array}{l}\text { Kompetensi individu } \\
\text { kekurangan satu tingkat }\end{array}$ \\
\hline 4 & 2 & 3,5 & $\begin{array}{l}\text { Kompetensi individu } \\
\text { kelebihan dua tingkat }\end{array}$ \\
\hline
\end{tabular}

\begin{tabular}{|c|c|c|l|}
\hline 5 & -2 & 3 & $\begin{array}{l}\text { Kompetensi individu } \\
\text { kekurangan dua tingkat }\end{array}$ \\
\hline 6 & 3 & 2,5 & $\begin{array}{l}\text { Kompetensi individu } \\
\text { kelebihan tiga tingkat }\end{array}$ \\
\hline 7 & -3 & 2 & $\begin{array}{l}\text { Kompetensi individu } \\
\text { kekurangan tiga tingkat }\end{array}$ \\
\hline 8 & 4 & 1,5 & $\begin{array}{l}\text { Kompetensi individu } \\
\text { kelebihan empat tingkat }\end{array}$ \\
\hline 9 & -4 & 1 & $\begin{array}{l}\text { Kompetensi individu } \\
\text { kekurangan empat tingkat }\end{array}$ \\
\hline
\end{tabular}

Setelah itu, setiap aspek dibagi menjadi dua kelompok yaitu Core Factor dan Secondary Factor, dengan rumus :

Dimana NCF : Nilai rata-rata core factor

$$
N C F=\frac{\sum N C}{\sum I C}
$$

NC : Jumlah total nilai core factor

IC : Jumlah item core factor

Sedangkan untuk rumus Secondary Factor adalah sebagai berikut :

Dimana NSF : Nilai rata-rata secondary factor

$$
N S F=\frac{\sum N S}{\sum I S}
$$

NS : Jumlah total nilai secondary factor

IS : Jumlah item secondary factor

Hasil perhitungan Core Factor dan Secondary Factor untuk setiap aspek dihitung nilai total presentasi yang kemungkinan berpengaruh dengan terhadap kinerja tiap-tiap profil.
Dimana $\mathrm{N}$
: Nilai Total aspek
$\mathrm{x} \% \quad$ : Nilai Persen core factor
$\mathrm{y} \% \quad$ : Nilai Persen secondary factor

$$
N=x \% N C F+y \% N S F
$$


Hasil akhir yang dilakukan oleh Profile Matching adalah melakukan ranking yang mengacu pada hasil perhitungan tertentu, dimana rumus yang digunakan adalah sebagai berikut :

Dimana $\mathrm{n} \% \quad$ : Nilai Persen ke-n

$$
\text { Ranking }=x \% N a+y \% N b+\cdots+n \% N m
$$

Nm : Nilai Total aspek ke-m

\section{METODE PENELITIAN}

Metode yang digunakan untuk evaluasi Sistem Informasi Pendaftaran Pasien IGD adalah Profile Matching, dimana dilakukan dengan mengambil data kualitatif berdasarkan penilaian kuesioner dari responden 1 orang programmer dan 2 orang Analis Sistem yang mempertimbangan kriteria-kriteria atau aspek yang diambil dari Standarisasi Internasional ISO 9126 yaitu Maintainability, Dependability, Efficiency, dan Usability, kemudian dilakukan revisi untuk memperbaiki kelemahan-kelemahan yang ditemukan pada saat implementasi. Lebih jelasnya,dapat dilihat tahap-tahap penelitian sebagai berikut :

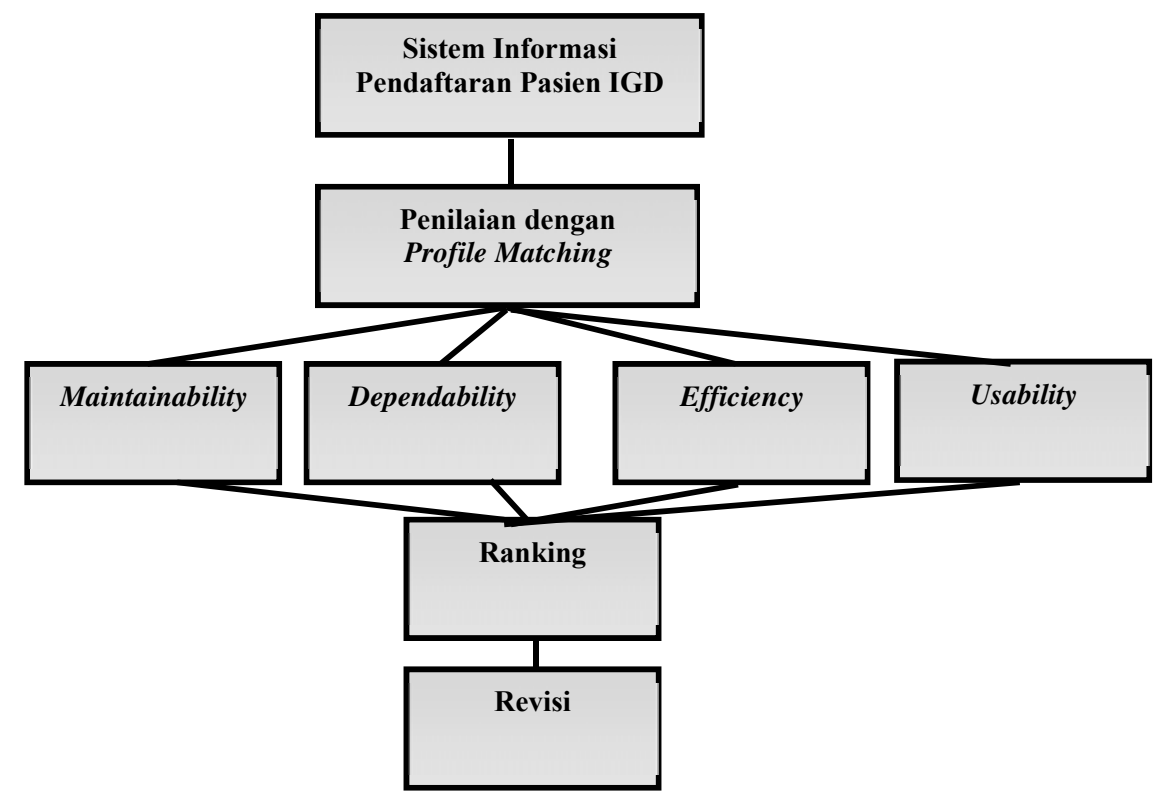

Gambar 1. Tahap-Tahap Penelitian

\section{HASIL DAN PEMBAHASAN}

Penilaian dilakukan responden dengan menguji kebutuhan Sistem Informasi Pendaftaran Pasien IGD atas dasar perancangan yang dibuat oleh (Katarina, 2003) yang terdiri dari Profil Interface, Database san Laporan.

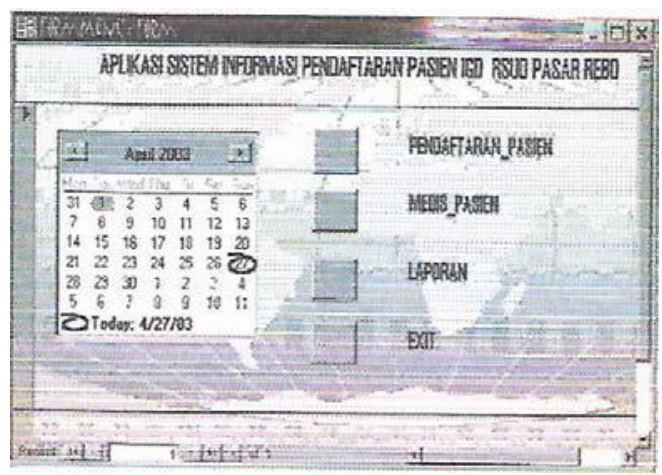

Gambar 2. Interface Sistem Informasi Pendaftaran Pasien IGD

Pertimbangan-pertimbangan yang dilakukan untuk penilaian mengikuti aspek dimana setiap aspek atau kriteria penilaian serta penentuan standar nilai berpengaruh dalam proses pemilihan (Kristiana, 2015), dari Profil Interface, Database, dan Laporan sebagai berikut : 
1) Maintainability; apakah sistem mudah dilakukan perbaikan kesalahan apabila diperlukan sehingga perlu memperhatikan design (rancangan) sistem.

2) Dependability; apakah sistem dapat mengikuti perkembangan teknologi yang mengacu pada reliability (kecenderungan sistem mengalami kegagalan dalam melakukan perintah), security (adanya resiko bagi pengguna), dan safety (kehandalan sistem dalam menangkal ancaman dari luar sistem).

3) Efficiency; apakah mempunyai ketersediaan ruang penyimpanan (memory) dan proses tidak berulangulang (time cycle).

4) Usability; apakah sistem mudah di mengerti atau mudah digunakan (user guide).

Penilaian dilakukan dengan menggunakan skala likert digunakan untuk mengukur sikap, pendapat, dan persepsi seseorang atau sekelompok orang tentang fenomena sosial (Sugiyono, 2012), penilaian tersebut diisi oleh responden sebagai berikut :

Tabel 2. Skala Likert

\begin{tabular}{|c|l|}
\hline \multicolumn{2}{|c|}{ Skala Likert } \\
\hline 1 & Sangat Kurang \\
\hline 2 & Kurang \\
\hline 3 & Cukup \\
\hline 4 & Baik \\
\hline 5 & Sangat Baik \\
\hline
\end{tabular}

Kemudian setiap aspek diberi nilai bobot untuk target Profil Interface, Database dan Laporan, antara lain :

Tabel 3. Aspek Maintainability

\begin{tabular}{|c|c|}
\hline Maintainability & Design \\
\hline Interface & 4 \\
\hline Database & 5 \\
\hline Laporan & 4 \\
\hline
\end{tabular}

Tabel 4. Aspek Dependability

\begin{tabular}{|c|c|c|c|}
\hline Dependability & Reliability & Security & Safety \\
\hline Interface & 4 & 5 & 3 \\
\hline Database & 4 & 4 & 4 \\
\hline Laporan & 3 & 4 & 3 \\
\hline
\end{tabular}

Setiap aspek diatas, dihitung nilai Gapnya, seperti berikut :

Tabel 7. Gap Aspek Maintainability

\begin{tabular}{|l|l|}
\hline Maintainability & Design \\
\hline Interface & -1 \\
\hline Database & 0 \\
\hline Laporan & -1 \\
\hline
\end{tabular}

Tabel 8. Gap Aspek Dependability

\begin{tabular}{|c|c|c|c|}
\hline Dependability & Reliability & Security & Safety \\
\hline Interface & 0 & 2 & 0 \\
\hline Database & 0 & 1 & 1 \\
\hline Laporan & -1 & 1 & 0 \\
\hline
\end{tabular}

Tabel 5. Aspek Efficiency

\begin{tabular}{|c|c|c|}
\hline Efficiency & Memory & $\begin{array}{c}\text { Time } \\
\text { Cycle }\end{array}$ \\
\hline Interface & 3 & 4 \\
\hline Database & 3 & 4 \\
\hline Laporan & 4 & 4 \\
\hline
\end{tabular}

Tabel 6. Aspek Usability

\begin{tabular}{|c|c|}
\hline Usability & User Guide \\
\hline Interface & 5 \\
\hline Database & 2 \\
\hline Laporan & 3 \\
\hline
\end{tabular}

Kemudian diberi bobot nilai Gap dan dihitung nilai core factor dan secondary factor, sampai mendapatkan nilai ranking yang dijelaskan pada tabel sebagai berikut :

Tabel 11. Bobot Nilai Gap, Core Factor, dan Secondary Factor

\begin{tabular}{|c|r|r|r|r|}
\hline $\begin{array}{c}\text { Maintainabilit } \\
y\end{array}$ & $\begin{array}{c}\text { Desig } \\
n\end{array}$ & $\begin{array}{c}\text { Core } \\
\text { Facto } \\
r\end{array}$ & $\begin{array}{c}\text { Secondar } \\
\text { y Factor }\end{array}$ & $\mathrm{N}$ \\
\hline Interface & 4 & 4 & 0 & 2. \\
& & & & 4 \\
\hline Database & 5 & 5 & 0 & 3 \\
\hline
\end{tabular}

Tabel 9. Gap Aspek Efficiency

\begin{tabular}{|c|c|c|}
\hline Efficiency & Memory & Time Cycle \\
\hline Interface & 0 & 0 \\
\hline Database & 0 & 0 \\
\hline Laporan & 1 & 0 \\
\hline
\end{tabular}

Tabel 10. Gap Aspek Usability

\begin{tabular}{|c|c|}
\hline Usability & User Guide \\
\hline Interface & 2 \\
\hline Database & -1 \\
\hline Laporan & 0 \\
\hline
\end{tabular}




\begin{tabular}{|c|r|r|r|r|r|r|}
\hline $\begin{array}{c}\text { Databa } \\
\text { se }\end{array}$ & 5 & 4.5 & 4.5 & 4.7 & 4.5 & 4. \\
\hline $\begin{array}{c}\text { Lapora } \\
\mathrm{n}\end{array}$ & 4 & 4.5 & 5 & 4.2 & 5 & 4. \\
\hline
\end{tabular}

\begin{tabular}{|r|r|r|r|r|r|}
\hline Laporan & 4.5 & 5 & 5 & 4.5 & $\begin{array}{r}4 . \\
8\end{array}$ \\
\hline
\end{tabular}

\begin{tabular}{|c|r|r|r|r|r|}
\hline $\begin{array}{c}\text { Efficien } \\
\text { cy }\end{array}$ & $\begin{array}{c}\text { Memo } \\
\text { ry }\end{array}$ & $\begin{array}{c}\text { Tim } \\
e \\
\text { Cycl } \\
e\end{array}$ & $\begin{array}{c}\text { Core } \\
\text { Fact } \\
\text { or }\end{array}$ & $\begin{array}{c}\text { Seconda } \\
\text { ry } \\
\text { Factor }\end{array}$ & $\mathrm{N}$ \\
\hline $\begin{array}{c}\text { Interfac } \\
e\end{array}$ & 5 & 5 & 5 & 5 & 5 \\
\hline $\begin{array}{c}\text { Databas } \\
e\end{array}$ & 5 & 5 & 5 & 5 & 5 \\
\hline
\end{tabular}

\begin{tabular}{|c|r|r|r|r|}
\hline Usability & \multicolumn{1}{|l|}{$\begin{array}{l}\text { User } \\
\text { Guide }\end{array}$} & $\begin{array}{l}\text { Core } \\
\text { Factor }\end{array}$ & $\begin{array}{l}\text { Secondary } \\
\text { Factor }\end{array}$ & N \\
\hline Interface & 3.5 & 3.5 & 0 & 2.1 \\
\hline Database & 4 & 4 & 0 & 2.4 \\
\hline Laporan & 5 & 5 & 0 & 3 \\
\hline
\end{tabular}

Tabel 12. Ranking Profile Matching

\begin{tabular}{|l|r|r|}
\cline { 2 - 3 } \multicolumn{1}{c|}{} & \multicolumn{1}{c|}{ Nilai } & \multicolumn{2}{c|}{ Ranking } \\
\hline Interface & 3.795 & 3 \\
\hline Database & $\mathbf{4 . 0 3 5}$ & $\mathbf{1}$ \\
\hline Laporan & 3.825 & 2 \\
\hline
\end{tabular}

Berdasarkan pada tabel 12 , nilai ranking yang paling tinggi adalah Database $(4,035)$ dikarenakan struktur database dapat dikatakan sudah baik; tidak ada kerangkapan data dan sesuai dengan aturan Normalisasi; Identifikasi field-field dapat dikatakan sudah jelas sehingga memudahkan pengguna melakukan pencarian data.

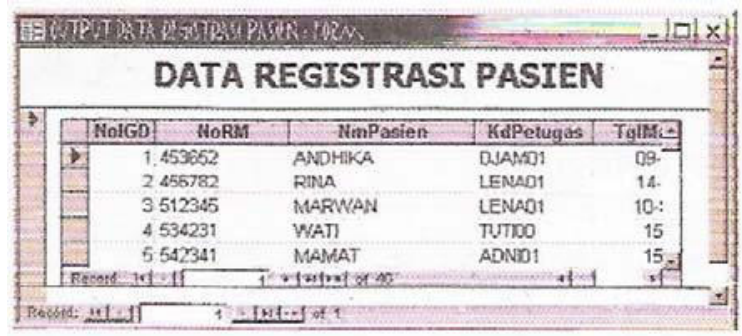

Gambar 3. Tampilan Database Sistem Informasi Pendaftaran Pasien IGD

Sedangkan untuk laporan, dapat dikatakan cukup karena terdapat laporan pasien yang berkunjung ke IGD, namun lebih baik jika terdapat gambar grafik kunjungan pasien sehingga memudahkan pihak manajemen RSUD Pasar Rebo menganalisa berapa banyak pasien yang mendatangi RSUD Pasar Rebo secara berkala.

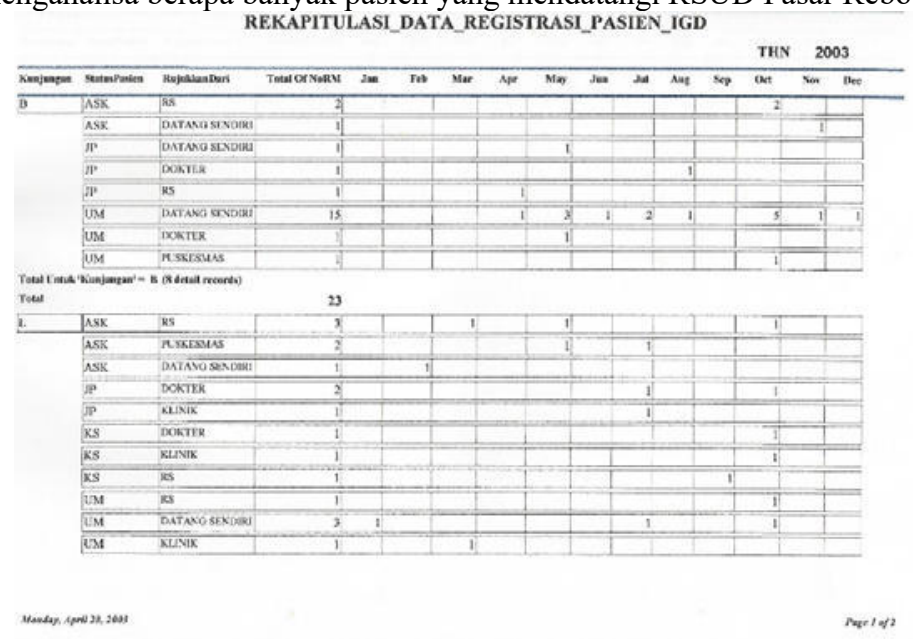

\section{Gambar 4. Tampilan Laporan}

Terakhir adalah Interface, mendapatkan posisi ketiga dikarenakan tampilan masih sangat sederhana dan kurang efisien, akan lebih baik jika dibuatkan menu bar sehingga dapat menghemat tempat dan tidak perlu membuat banyak form.

Berdasarkan penilaian Profile Matching di atas adalah walaupun tampilan masih kurang efisien namun secara garis besar fungsional dari sistem informasi pendaftaran pasien IGD dapat dikatakan cukup baik karena dilihat dari segi penginputan dan penyimpan data, sehingga pengguna tidak perlu lagi melakukan pencatatan secara manual. Sistem Informasi Pendaftaran Pasien IGD RSUD Pasar Rebo dapat dikatakan sesuai dengan kebutuhan (user friendly) dan mempermudah pekerjaan RSUD Pasar Rebo dalam penanganan pasien IGD. 


\section{SIMPULAN DAN SARAN}

\section{A. Simpulan}

1) Nilai ranking yang paling tinggi adalah Database $(4,035)$ dikarenakan struktur database dapat dikatakan sudah baik; tidak ada kerangkapan data dan sesuai dengan aturan Normalisasi; Identifikasi field-field dapat dikatakan sudah jelas sehingga memudahkan pengguna melakukan pencarian data.

2) Ranking kedua adalah laporan $(3,825)$, dapat dikatakan cukup karena terdapat laporan pasien yang berkunjung ke IGD.

3) Ranking ketiga adalah Interface (3,795), dikarenakan tampilan masih sangat sederhana dan kurang efisien.

4) Walaupun tampilan masih kurang efisien namun secara garis besar fungsional dari sistem informasi pendaftaran pasien IGD dapat dikatakan cukup baik karena dilihat dari segi penginputan dan penyimpan data, sehingga pengguna tidak perlu lagi melakukan pencatatan secara manual.

5) Sistem Informasi Pendaftaran Pasien IGD RSUD Pasar Rebo dapat dikatakan sesuai dengan kebutuhan (user friendly) dan mempermudah pekerjaan RSUD Pasar Rebo dalam penanganan pasien IGD.

B. Saran

1) Pada Laporan, lebih baik jika terdapat gambar grafik kunjungan pasien sehingga memudahkan pihak manajemen RSUD Pasar Rebo menganalisa berapa banyak pasien yang mendatangi RSUD Pasar Rebo secara berkala.

2) Pada Interface, dibuatkan menu bar sehingga dapat menghemat tempat dan tidak perlu membuat banyak form.

3) Hasil penelitian ini dapat dikembangkan dalam penelitian lanjutan dengan model atau pendekatan lain yang masih relevan dengan penelitian ini.

\section{DAFTAR PUSTAKA}

Fiati, R. (2015). Pemanfaatan Model Profile Matching Untuk Penentuan Mustahik. Seminar Nasional Teknologi Informasi dan Multimedia. STMIK AMIKOM Yogyakarta, 2.2-61-2.2-66.

ISO/IEC. (9001). ISO/IEC 9126 - Software Product Evaluation-Quality Characteristic and Guidelines for their Use. Genewa: ISO Standard.

Katarina, D. (2003). Analisa Dan Desain Sistem Informasi Pendaftaran Pasien IGD Di RSUD Pasar Rebo. Universitas Gunadarma. Depok. Jawa Barat.

Kristiana, T. (2015). Penerapan Profile Matching Untuk Penilaian Kinerja Pegawai Negeri Sipil (PNS). Jurnal Pilar Nusa Mandiri Vol.XI, No. 2, 161-170.

Nasyriyah, R., Arham, Z., \& Aini, Q. (2016). Profile Matching and Competency Based Human Resources Management Approaches for Employee Placement Decision Support System (Case Study). Asian J. Applied Sci., 9 (2), 75-86.

Sugiyono. (2012). Metode Penelitian Kuantitatif Kualitatif dan $R \&$ \& . Bandung : Alfabeta.

Turban, E. Sharda, R. \& Delen, D. (2011). Decision Support and Bussiness Intelligence Systems. Prientice Hall. New Jersey. 